\title{
MORALITY, LAW, AND PRACTICAL REASON
}

\author{
Enrique Benjamin R. Fernando III \\ University of the Philippines Diliman, Philippines
}

\begin{abstract}
Morality is a normative system of guidance that figures into practical reason by telling people what to do in various situations. The problem, however, is that morality has inherent gaps that often render it inefficacious. First, it may be indeterminate due to the high level of generality in which its principles are formulated. Second, moral terms such as 'good' and 'right' may be so vague that they fail to specify the requisite behavior. And third, its subjective aspect, which is a product of personal experience, generates moral disagreement and thereby creates coordination problems that frustrate society's collective moral aims.

The objective of this article is to advance the thesis that morality must sometimes depend on law as a supplementary source of practical reason, a dependence which can be explained in terms of three essential features of law: its institutional character, its claim to authority, and its status as a second-order exclusionary reason for action. It shall then be explained how these three features enable law to make difficult decisions on behalf of individuals, define objective standards of conduct, and solve coordination problems, respectively, and in doing so, manage to fill in the gaps of morality mentioned above. Hence, it will be argued that law is also a normative system that helps people achieve their moral aims, notwithstanding the fact that it guides human behavior through a different logic and mode of operation from those of morality.
\end{abstract}

\section{INTRODUCTION}

This article aims to advance the thesis that morality sometimes depends on law as a source of practical reason. That is to say, in situations wherein morality is unable to tell people what they ought to do, law provides the guidance that they need to achieve their moral aims, especially in everyday dilemmas that are so complex that morality by itself is inadequate to resolve them. In these situations, it must rely on the aid of law as a conceptually distinct but supplementary system of norms that guides human behavior in a different way. It is not claimed, however, that its dependence on law is one of the conceptual features of morality. On the contrary, it is conceded from the onset that this relation, if it exists, is merely a contingent one; in other words, it is not always the case that morality depends on law because they are relatively autonomous systems with their own internal rules and logic. 
This paper shall elucidate the essential features of morality and law that make this relation possible. To this end, the discussion will be divided into three main parts. First, it shall explain why morality is sometimes incapable of providing people with practical guidance. Second, it shall describe three essential features of law that enable it to function as a source of practical reason. And third, it shall conclude by illustrating how these features enable law to fill in some of the gaps of morality in aid of practical reason.

\section{MORALITY}

\section{The Requirements of Reason and Impartiality}

Morality is a system of norms that is characterized in terms of two indispensable requirements: first, that it be guided by reason, and second, that it be impartial to the interests of individuals (Rachels and Rachels 2018, 13).

\section{Reason}

First, morality is a rational enterprise in that its normative, evaluative, or substantive judgments must rest on sound and cogent reasons. This means that moral judgments are not matters of personal taste. They may be valid or invalid depending on the quality of the reasoning that has been deployed in constructing them. This also means that there are objective grounds upon which moral arguments can be compared; those that are supported by good reasons are ordinarily said to possess greater weight than those that are not. For example, arguments against abortion that are premised upon its harmful psychological effects are said to be better than those that are based exclusively on religious doctrine. This is because the former can be defended by reasoning from an empirical investigation of the facts, whereas the latter, because they are based on religious doctrine, lie beyond the realm of rational discourse.

It should be noted that not all reasons for acting morally are necessarily moral ones. Prudential reasons often motivate moral actions as well. For example, a college student may confess to university officials that the members of his fraternity were responsible for inflicting severe physical injuries to an aspirant merely out of fear that he will be sanctioned unless he cooperates with the administration. Otherwise, he would have had no reason to come forward as a whistleblower without the threat of sanction. Similarly, a churchgoer may agree to make a charitable donation at a parish fundraiser only due to the pressure generated by seeing other parishioners issuing checks of their own. Without this external motivation, he may have been able to resist any moral reason urging him to make a donation. These examples illustrate that moral reasons are not always sufficient to motivate moral action as well, and so they may need to be complemented by other kinds of reasons for moral outcomes to be attained.

\section{Impartiality}

Second, morality is impartial in that it gives equal consideration to the interests of stakeholders. This feature is often interpreted as a formal rather than substantive requirement of morality. According to this interpretation, to give equal consideration 
is to treat like interests alike: an interest should be valued as an interest no matter whom it belongs to. Arbitrary factors such as race, gender, or religion cannot be used to disqualify a person from being factored into one's deliberation as long as he or she has a relevant interest at stake. Hence, to give people equal consideration is simply to take their interests into account when warranted, even if doing so does not guarantee a decision in their favor (Singer 1993, 21).

This does not mean that all interests are equal in an absolute sense. On the one hand, it does not follow from the concept of impartiality that the best moral decision brings about an equal amount of good to every stakeholder because doing so might entail treating others unjustly. For example, a corporate manager who deliberately withholds a promotion from an employee who comes from a wealthy family and awards it to someone less deserving instead is, in principle, acting as immorally as someone who discriminates against workers on arbitrary grounds. In spite of the natural advantages that they were born with or the resources, accolades, and relationships that they have accumulated throughout their lifetimes, they are in legitimately acquired positions to benefit from their own hard work.

It also does not follow that the best moral decision gives equal weight to competing interests. Some interests may be of greater value to the decisionmaker in the morally relevant respects, thereby making it immoral to fail to consider these factors. This occurs, for instance, when some people have suffered so severely from chronic poverty that they are morally entitled to have their basic needs prioritized over the luxurious aspirations of the privileged. This does not mean that the interests of other people ought not to be given weight as well; after all, every person deserves to have their interests taken into consideration. However, morally relevant differences do entail that some interests carry greater weight than others and should thus be treated accordingly in the balance of reasons.

Hence, all that impartiality requires is for individuals with interests to be included within the sphere of moral consideration, even if their interests are not weighted equally or even if it results in unequal outcomes. In Ronald Dworkin's words $(2002,12)$, equality simply requires us to treat people as equals as opposed to treating them equally. However, this is easier said than done, for there are many reasons for people to fail to act impartially. They may feel that they are justified in doing what is in their own best interests, prioritize the needs of a loved one over that of a stranger, or simply misjudge what acting impartially requires. Indeed, when making moral decisions, one cannot underestimate the incredible difficulty of detaching oneself from one's situated point-of-view in favor of what Thomas Nagel $(1986,171)$ calls the "view from nowhere" - the objective standpoint from which no one is valued as more important than anyone else, including friends and family members. Sometimes, individuals must simply be compelled to act impartially in order for them to do so.

\section{Morality as Practical Reason}

It is easy to see how morality is a system of guidance by virtue of being a rational and impartial enterprise. Like any other normative system, it purports to tell people what to do. In light of this purpose, it equips moral agents with various tools to resolve 
practical conflicts, each of which fulfills a different function and possesses a unique scope of application.

First, morality improves practical deliberation by helping people evaluate good reasons for action. On many occasions, it provides general substantive principles from which specific moral judgments can be deduced. These principles vary in terms of their level of generality. Some of them are broad in application, such as the general principle that stealing is wrong, while others are more specific, such as the principle that car manufacturers are responsible for the safety of their customers. On other occasions, morality provides formal criteria for determining the optimal moral decision. For example, some moral theories test whether a given maxim is universalizable and can thus be elevated to the status of moral law. Others measure the moral worth of an action in terms of its consequences.

Second, morality improves practical deliberation by setting standards for how competing interests are to be weighed. It has been debated, for instance, whether terminally ill patients have a weaker claim to scarce medical resources than a forty-yearold mother who has been diagnosed with cancer (Harris 2016). For problems of this sort, morality provides insight on whether one life has more value than another, whether one's chances of medical recovery make a moral difference, or how much weight should be given to the interests of third parties such as the mother's young children. Furthermore, morality also provides frameworks that governments consult in designing political, economic, and social policies. For example, while there is nearly universal consensus that the economic poor is entitled to special consideration in the distribution of resources, there is far less agreement on what kinds of resources they really need, whether welfare payments should be made conditional, or whether social programs should prioritize developmental needs over basic ones. Morality enters the equation by giving insights on how governments can balance short and long-term solutions against each other (Lucas 1977, 262). This does not mean that the moral philosopher can replace the economist who creates economic policies. However, he can contribute by formulating principles for distributing resources, drafting frameworks for sustainable development, or expressing his dissent against policies that undermine human dignity.

These substantive principles, formal methods, and standards are only some of the apparatus provided by morality in aid of practical reason. An entire arsenal of tools may be in play when someone makes a moral decision. It equips him to solve anything from highly theoretical conundrums to concrete moral dilemmas. Unfortunately, however, there are instances where it is incapable of solving practical conflict. Therefore, the interest of this paper is to explain why morality falls short, notwithstanding its wealth of internal resources. Its gaps, it shall be shown, are inherent to its structure for three reasons. These may be referred to as the Argument from the Nature of Morality, the Argument from the Nature of Moral Language, and the Argument from the Nature of Subjective Moral Experience.

\section{The Gaps of Morality}

This section shall discuss three kinds of gaps that render morality inoperative as a source of practical reason. The gap of indeterminacy arises from the nature of 
morality itself, the gap of vagueness arises from the nature of moral language, and the gap of moral disagreement arises from the nature of subjective moral experience.

\section{The Argument from the Nature of Morality: Indeterminacy}

Morality is indeterminate when it fails to point to a uniquely correct answer to a moral problem. This occurs for three main reasons. First, precisely because morality purports to guide human behavior in a virtually limitless range of cases, its precepts must necessarily be formulated in highly general terms. The best it can do is establish some broad and relatively elastic principles that can be modified to fit as many concrete situations as possible. The trade-off, however, is that such general principles only cover relatively "easy" cases where the moral thing to do is clear; there will inevitably arise hard cases whose nuances are so novel or complex that no general moral principle can hope to provide a determinate solution. As Bernard Williams (1972, xviii) points out, it is highly doubtful that even professional philosophers can always deduce particular moral conclusions from unnuanced a priori premises all of the time. Second, even if a moral agent had complete and perfect knowledge of the situation, moral problems pose questions of value rather than questions of facts. No amount of factual investigation will relieve him of a normative question's sting. This is aggravated by the possibility that competing values may be incommensurate, or conversely that they may be commensurate but bear such an equal amount of weight that comparing their results in a dead heat. That morality cannot provide final answers to hard problems should thus come as no surprise. After all, moral problems are inherently controversial; once determinate answers are discovered, they cease to fall under the jurisdiction of morality (or moral philosophy) and are thereafter relegated to the domain of science (Nowell-Smith 1954, 15). The third is the meta-level reason that it is not always obvious why one should act morally, to begin with. While morality may provide the resources for determining the correct moral answer, it may fail to persuade the agent why he should select from within the range of moral options at all. It is not uncommon for people to ask, for example, "Why is it bad to be bad?" It is often unclear what harm will accrue from acting immorally, or at least, prudentially in the name of self-interest (Bloomfield 2008, 252).

The problem of indeterminacy may be observed in the following example. Consider a man named Smith who is going for a swim at the beach. He suddenly hears the cries of two children who are drowning and calling for help. Smith looks around and realizes that no other adult sees them drowning. Unfortunately, both children swam so far out from the shoreline that only one of them can be reached in time. The child who will not be saved will certainly drown, so Smith must immediately decide whom he shall rescue.

Furthermore, it just so happens that they are identical twins who are exactly alike in every respect. They are even drowning at points equidistant from where Smith is currently located, which means that the chances of saving one are equally as good as those of saving the other. In such a case of equipoise, it is impossible to determine whether there is any good reason to save one twin over the other. Nor is there enough time to make a well-reasoned and impartial decision given the urgency of the situation. The problem is that Smith is not a very good swimmer himself. Attempting to save them would place him in danger of being dragged down by the undertow. At this 
moment, Smith is faced with genuine uncertainty. His first problem concerns which boy he should save, assuming there were a morally correct answer to this dilemma. His second is whether he is even morally obligated to attempt saving them at all. Given that he is not a capable swimmer, no one would blame him for refusing to gamble on his own life. It feels far more intuitive to act in self-interest and try calling for help instead, even if he knows that this will be futile. Indeed, he surmises, there is no absolute moral duty to save the life of a stranger at the cost of one's own, even if that stranger is a child. He concludes that it is justified to act in self-preservation.

\section{The Argument from the Nature of Moral Language: Vagueness}

The second gap of morality exists because the meanings of moral terms are notoriously vague. A term is vague when it has no clearly defined meaning (Gorovitz et al. 1979, 157) or when its extension or range of applications is unclear (Hospers 1997, 22). For example, St. Thomas Aquinas (1988, 46-47) claimed that it was a selfevident principle of morality that one ought to do good and avoid evil. People understand what this entails in broad terms. They interpret 'do good' to mean that one ought to love his neighbor, help the poor, or tell the truth, and 'avoid evil' to mean that one ought not to kill other people, steal their possessions, or deceive them for personal gain. The problem is that there are many situations in which it is unclear what 'good' translates to. People may have a rough idea of what it means but may also be uncertain about what exactly is required of them. The vagueness of such terms has been attributed to the "open texture" of language. On this view, general terms such as 'good' or 'right' have a core of meaning, and standard uses that everybody agrees are appropriate, but there is also a penumbra of uncertainty and borderline cases about their correct applications (Hart 1958, 607). It may also be attributed to the fact that 'good' is like 'yellow'; such terms denote simple concepts that cannot be broken down into smaller parts and explained in simpler terms (Moore 1971 [1903], 7).

Unfortunately, the problem of vagueness does not disappear even when people nuance the meaning of 'good' or 'right' to their specific contexts. This occurs, for instance, when a reformed convict resolves to act like a "good" citizen or when a businessman makes it a rule always to treat his employees "rightly." The issue, however, is that phrases such as 'good citizen' or 'treat employees rightly' are still vague. They can be interpreted to mean anything from doing the bare minimum of not subjecting workers to sub-standard working conditions to going beyond their duty and giving them generous bonuses. Whatever the case may be, people find themselves second-guessing whether they are doing what they morally ought to do. A logical analysis of the linguistic properties of moral terms reveals two reasons why.

Supervenience The first is that terms such as 'good' and 'right' are supervenient, which means that they are evaluative terms whose meanings are logically dependent on factual and descriptive criteria (Hare 1984, 1). This definition applies to both moral and non-moral uses of these terms. For example, people who point to an object and say, "This is a good X," will often be asked, "What is good about it?" This is because the word 'good' cannot logically stand on its own. The 'what' must be filled out by a noun that belongs to a class of objects that are said to be good 
by virtue of satisfying certain publicly shared criteria of value. Hence, the proposition "A is a good X" means that A is an entity that is an X, and A possesses characteristics that are said to make an $\mathrm{X}$ good. In this proposition, it is ' $\mathrm{X}$ ' that does the logical work of expressing the good-making standards against which A will be measured, not the word 'good' itself. This does not mean that 'good' is otiose. For instance, in many cases, it adds the illocutionary force of commending or prescribing to a proposition (Searle 1962, 425). Thus, in ordinary parlance, 'A is a good car' can be taken to mean that if one were to purchase a car, one ought to consider selecting one that has characteristics that are comparable to those of A. Similarly, 'A is a good citizen' is taken to mean that one ought to behave like A because he has certain virtues that make a citizen good. In this example, 'good' has a formal rather than substantive function; it designates what one ought to choose or whom one ought to emulate rather than what one ought to do.

'Right' is supervenient in the same way as 'good' (Hare 1952, 153). In the proposition 'Jones acted rightly by paying his employees overtime,' the correct use of the word 'rightly' depends on whether the standard of giving overtime pay was actually satisfied. If Jones did not pay his employees commensurately for working beyond office hours, then he could not have treated them rightly. Thus, 'rightly,' by itself, cannot describe how an employer ought to act. Once again, the moral term in the proposition has a formal rather than substantive function because its contribution is to commend Jones' action and to designate it as the kind of behavior that employers ought to reproduce, rather than specify what 'rightly' means.

Predicative and Attributive Adjectives The second reason why moral terms are vague is explained by P.T. Geach's (1956) distinction between predicative and attributive adjectives. In the phrase 'an A B'-where ' $A$ ' is an adjective and ' $\mathrm{B}$ ' is a noun - ' $A$ ' is a predicative adjective if the predication 'is an A B' can be logically split into a pair of predications 'is $\mathrm{A}$ ' and 'is a $\mathrm{B}$.' For example, ' $\mathrm{X}$ is a blue bird' can be logically split into:

$$
\begin{gathered}
\left(\mathrm{A}_{1}\right) \text { ' } \mathrm{X} \text { is blue'; and } \\
\left(\mathrm{B}_{1}\right) \text { ' } \mathrm{X} \text { is a bird.' }
\end{gathered}
$$

Moreover, the following kind of inference can be validly drawn from a sentence containing a predicative adjective:

$\left(\mathrm{P}_{1}\right) \mathrm{X}$ is a blue bird.

$\left(\mathrm{P}_{2}\right)$ A bird is an animal.

$\therefore \quad \mathrm{X}$ is a blue animal.

On the other hand, ' $\mathrm{A}$ ' is an attributive adjective if the predication 'is an A B' cannot be logically split in the same manner. For example, ' $\mathrm{Y}$ is a large mouse' cannot be split into:

$$
\begin{aligned}
& \left(\mathrm{A}_{2}\right) \text { 'Y } \mathrm{Y} \text { is large.'; and } \\
& \left(\mathrm{B}_{2}\right) \text { ' } \mathrm{Y} \text { is a mouse.' }
\end{aligned}
$$


This is because 'large' is a relative term whose meaning depends on the size of the average mouse. ' $\mathrm{Y}$ is a large mouse' really means something like ' $\mathrm{Y}$ is big for a mouse.' Consequently, the kind of inference that applies to ' $\mathrm{X}$ is a blue bird' cannot be derived from premises containing attributive adjectives. For example, the following syllogism is illegitimate:

$\left(\mathrm{P}_{3}\right) \mathrm{Y}$ is a large mouse.

$\left(\mathrm{P}_{4}\right)$ A mouse is an animal.

$\therefore \quad \mathrm{Y}$ is a large animal.

The main difference is that predicate adjectives modify nouns in the same way that predicates modify the subjects of sentences (e.g., This bird is blue), whereas attributive adjectives come before the nouns and constitute part of the subject (e.g., A good car will give you around 12,000 miles a year for five years). 'Good' is always an attributive adjective because its meaning is intimately connected with the substantive that it modifies; in other words, 'good' is part of the noun phrase, and its meaning is logically tied to standards of value that are associated with the noun. For example, the meaning of 'good' in 'Jones is a good employer' depends on accepted criteria for what makes an employer commendable. It cannot be split into the following propositions without losing its original meaning:

$\left(\mathrm{A}_{3}\right)$ 'Jones is good.'; and

$\left(\mathrm{B}_{3}\right)$ 'Jones is an employer.'

$\left(A_{3}\right)$ is vague because 'good,' as discussed, is supervenient. Anyone to whom $\left(A_{3}\right)$ is uttered is likely to ask in what sense Jones is good. It certainly does not follow from 'Jones is a good employer' that Jones is good in a moral sense. Jones may be a good employer in that he gives his employees overtime pay when deserved, but he may be morally reprehensible in every other aspect as a human being. Being a good employer can logically co-exist with being morally good as well. However, this is not logically verifiable through a purely linguistic analysis of the word 'good,' for much of its meaning is determined by publicly shared criteria associated with 'employer.' Thus, the inference below does not always follow:

$\left(\mathrm{P}_{5}\right)$ Jones is a good employer.

$\left(\mathrm{P}_{6}\right)$ An employer is a man.

$\therefore$ Jones is a good man.

Similar examples can be made of the word 'right' because an act, treatment, or motive would be right only in relation to designated standards of right behavior. Ultimately, the reason why moral terms are vague - whether as supervenient terms or as attributive adjectives - is because they are opaque. They do not express what makes a person, object, or action good or right. Their meanings are logically dependent on the nouns that they modify and whose standards of value must be discovered through empirical investigation rather than moral reasoning alone. In short, many substantive principles cannot be derived from the meaning of moral terms alone. Individuals must 
sometimes look to criteria-setting institutions and normative systems other than morality in order to clarify what is required.

\section{The Argument From Subjective Moral Experience: Moral Disagreement}

As a normative ethical theory, Subjectivism believes that what is morally good is whatever one likes (Gensler 2018, 22). As a meta-ethical theory, it is the view that moral properties are determined by the subjective responses of moral appraisers to certain actions (Van Roojen 2015, 99). It is not the business of this paper to evaluate the merits of Subjectivism. Rather, it explores the implications of the fact that one's personal experiences shape his moral views. After all, one cannot help but view right and wrong through the lens of what one has been through and how one has responded to these events. One may associate positive experiences with what is morally right, i.e., how one morally ought to be treated, and negative experiences with what is morally wrong, i.e., how one morally ought not to be treated. Morality derived from subjective experiences is prone to error; either a person's misplaced values distort his interpretation of his experiences, or he may simply arrive at faulty conclusions due to lapses in his reasoning. These errors, of course, can be offset by the study of moral philosophy or the reception of advice from other persons. However, in any case, despite human fallibility, there is some truth to J.L. Mackie's $(1978,106)$ claim that part of morality is "invented" when one chooses which moral principles to adopt in life. This is not to say that there actually individuals who identify themselves as fullblooded subjectivists, only that it is part and parcel of a person's moral life that personal events influence his conception of moral right and wrong.

The main implication of subjective moral experience is that it generates substantive disagreement. People who come from different backgrounds or go through different experiences inevitably espouse divergent moral views over certain issues. While this may not affect the personal moral decisions that they make, it does create gaps situations where large groups of people need to coordinate their behavior to achieve their shared moral aims. These gaps are exposed when it becomes difficult to settle not only which moral aims are more important (if any) but the methods by which they are to be achieved (if possible). Furthermore, large-scale coordination problems may be aggravated by other extraneous factors that are exacerbated by subjective disagreements, such as the uncertainty of how widely accepted one's goals are, the lack of information concerning how others plan to attain those shared goals, or the probability that the desired outcomes will be realized at all. In these situations, morality cannot supply the pertinent information needed to make the optimal decision, especially since they are guided by their subjective moral standards.

For instance, almost everyone within a community might accept the moral aim of improving the general welfare, but there is a need for them to coordinate their behavior to optimize their efforts. Some members, however, might believe that improving the general welfare requires lifting the economic poor out of poverty, while others might believe that this requires promoting sustainability to preserve the environment and promote public health. There might, however, be more granular moral disagreement within each group. In the former, some may believe that social safety net programs should be funded, while others may object to this because it 
promotes dependency. In the latter, some may believe that reforestation projects should be funded, while others might object because it diverts resources away from subsidizing green technology that industrial factories can utilize to lower their carbon emissions. Even if the community were somehow to arrive at a consensus about which project to prioritize, there would still be the problem of determining how to execute it. For example, if a certain amount of funds is needed to implement the project, how will the money be raised? This poses additional moral questions as well. Should large corporations absorb the burden and be required to pay a special tax as the largest polluters in the name of fairness, or should ordinary consumers be required to pay a value-added tax on their purchases in the name of equality? Is the imposition of a new tax even justified, or can funds be diverted away from some other community project that is not as morally urgent? On top of such issues, a variety of smaller, nested coordination problems may first need to be addressed before the overall coordination problem can be solved. In such large-scale scenarios, morality has gaps insofar as it does not provide instructions about how the community should move forward. It lacks the resources to resolve subjective disagreement, the standards to compare incommensurate values, the conventions for making large-scale decisions, and the coordination mechanisms to organize collective behavior.

\section{LAW}

Before explaining how morality sometimes depends on law as a source of practical reason, it is necessary to discuss three essential features of law that enable it to serve this purpose: its institutional character, its claim to authority, and its function as a second-order exclusionary reason for action. Law, like morality, has been described as a normative enterprise of subjecting human conduct to the governance of rules (Fuller 1964, 106). In no way is it claimed, however, that law is an exact substitute for morality. Legal rules operate on a different logic, execute different functions, and attain many different outcomes than moral ones. Thus, it is important to carefully identify the ways in which they differ to understand how law does not possess the same gaps as those of morality.

\section{The Institutional Character of Law}

The institutional character of law arises from the existence of law-applying institutions charged with the promulgation and enforcement of legal norms and the regulation of disputes that arise from their application. These institutions claim to occupy a position of supremacy within society and to possess the authority to legitimize or outlaw all other normative systems and institutions ( $\operatorname{Raz} 1979,43)$. In doing so, they narrow both the range of reasons - moral or otherwise - that an individual may factor into his deliberations and that of the actions that he is allowed to perform.

An important consequence of its institutional character is that law has its limits; that is, legal systems can only apply norms that are connected with the operations of their institutions. There are two important implications that result from this restriction. First, some justificatory standards - moral or otherwise - lie outside of law's institutional 
scope. These standards can only be legal if they possess the requisite institutional connections or are valid under what is commonly referred to as the rule of recognitiona customary rule by which the officials of a legal system determine whether a norm is legally binding (Hart 1961, 103). For example, in many jurisdictions, a norm must have been enacted as a statute by Parliament, recognized by courts as judicial precedents, or elevated to the status of a legal custom in order to be considered law. This does not mean that legal institutions cannot enforce moral values, nor does this mean that legal norms cannot achieve moral aims. Some might even say that there are necessary connections between law and morality — such as the fact that both are normative systems with moral aims - without conceding that law's validity conceptually depends on morality (Gardner 2012 , 48). On this view, law is supplementary to but distinct from morality; its norms may be moral but are not valid because they are moral. The second implication is that law is binding regardless of its moral merit; that is to say, legal institutions cannot impose external qualifications of validity. Legal norms are applied because they have the status of law, not because they are morally right. Otherwise, imposing moral conditions of validity would either undermine the bona fide rules of institutions or validate norms that lie outside of their scope.

What thus sets law apart from other systems of norms is not that it provides superior reasons for action. It is not even that its institutions possess better theoretical resources for resolving practical conflicts. Rather, its distinguishing feature is that its institutions have the power to make authoritative determinations on contentious issues, regardless of how deeply or widely people might disagree with them. Hence, law differs from morality in that while individuals may choose whether to act in accordance with their moral obligations, they are not free to ignore their legal ones. Law, therefore, guides behavior in a way different from morality. It is backed by lawapplying institutions and compels individuals to behave according to the prescribed standards of conduct, deviations from which often merit some kind of sanction or reprimand (Austin 1998, 15). In this regard, law, unlike morality, has an entire coercive system in place for certain compelling forms of behavior. Moreover, this additional feature is absolutely critical, for, as Frederick Schauer $(2015,50)$ points out, individuals may act in consistency with law or morality but not because of law or morality. Sometimes, they need some motivational reinforcements to do what they ought to do. Fortunately, legal institutions are able to establish and operationalize their entire repertoire of coercive mechanisms to give people additional reasons for action, namely, prudential ones. ${ }^{1}$ However, the fact that legal institutions make final and authoritative determinations about what must be done does not mean that they cannot morally err. It simply means that their norms are binding even when they are mistaken.

\section{Authority}

Law's claim to authority is best understood by means of an example. Consider two individuals who refer their dispute to an arbitrator for resolution and who agree to abide by his decision regardless of the outcome. The arbitrator happens to be a respected authority figure. By making this agreement, they effectively render the arbitrator's decision as a reason for the action; they will do what he says simply 
because he will have said it. However, the fact of his decision is unlike any other reason that either disputant offers in arguing his case. This is because his decision will be based on the reasons that will be presented to him insofar as it will sum them up and reflect the outcome. Moreover, the decision is meant to replace the reasons on which it depends. In agreeing to obey his decision, the disputants decide in advance to honor his judgment of the balance of reasons instead of their own. Henceforth, his decision will settle what they ought to do (Raz 1990a, 121).

From this example, $\operatorname{Raz}(1994,215)$ derives the following theses that comprise the service conception of authority:

The dependence thesis: All authoritative directives should be based, among other factors, on reasons which apply to the subjects of those directives and which bear on the circumstances covered by the directives. Such reasons I shall call dependent reasons.

The normal justification thesis: The normal and primary way to establish that a person should be acknowledged to have authority over another person involves showing that the alleged subject is likely better to comply with reasons which apply to him (other than the alleged authoritative directives) if he accepts the directives of the alleged authority as authoritatively binding, and tries to follow them, than if he tries to follow the reasons which apply to him directly.

The pre-emption thesis: The fact that an authority requires performance of an action is a reason for its performance which is not to be added to all other relevant reasons when assessing what to do but should replace some of them.

The dependence thesis is explained by how the decision of the arbitrator will be based on the justifications that will be presented to him and reflect the sum of their weights, guaranteeing that the interests of both disputants will be taken into account. The normal justification thesis is explained by how the decision will become an additional reason for action for the disputants. This will occur because the recognition of the arbitrator's authority makes it more likely for the disputants to act accordingly than they would have in a situation where no such intervention had been made. Finally, the pre-emption thesis is explained by how the arbitrator's decision will replace the original justifying reasons that will have been presented. Should either disputant be asked why he behaved in a certain manner, he will be able to cite the fact of the decision as a reason for action without having to invoke any of the original arguments that he offered in his favor. In other words, the ultimate reason for action can be identified solely by reference to the outcome of the arbitration without needing to explain any of the original reasons that led to the decision. Such is the concept of authority.

The three theses are collectively referred to as the service conception of authority because they express the view that the function of authority is to serve the governed (Raz 1986, 56). Law satisfies this function by guiding individuals to act in conformity with the reasons that bind them in a manner that is easy to obey, regardless of what its content may be. The ways in which law accomplishes this function can be 
derived from the service conception. First, in relation to the dependence thesis, law incorporates the moral and non-moral values of society in a manner that reflects their relative importance. For example, a law against adultery may be intended to promote the moral value of fidelity and the socially desirable goal of family cohesion, while a law that sets the income tax rate may balance the liberty of taxpayers against the goal of generating revenue for government projects. On this view, law expresses how individuals ought to act after the relevant considerations have been debated and weighed by lawmakers in Congress or Parliament. Second, in relation to the normal justification thesis, the law serves as an additional reason for action that binds independently of moral norms, even when it goes against the balance of reasons. For instance, although Robin Hood may have good reason to believe that stealing from the rich and giving to the poor would improve the general welfare, he is forbidden from doing so by the law against theft. The law binds on the basis of its own rules, regardless of how persuasively one reasons against it. Third, in relation to the pre-emption thesis, law replaces the reasons that people have for pursuing a specific course of action. In doing so, it spares people the burden of performing their own moral calculations. It simply communicates what it prescribes on matters of adultery, taxation, and theft. No further discussions or judgments need to be made. It is in this manner that law is a source of authority that serves the governed: it makes it easier for them to do what they ought by making decisions for them in advance and thus making them more likely to comply with right reason.

\section{Law as a Second-Order Exclusionary Reason for Action}

It has been said that law must be capable of making a practical difference in human behavior; that is to say, it must be capable of motivating individuals to act differently from how they might have without its authoritative guidance (Shapiro 1998, 493). Moreover, law must be seen as giving what are known as "peremptory" and "content-independent" reasons for action. A reason is peremptory when it forecloses independent deliberation on the merits of an action by making one think that the fact that the law directs him to act accordingly is by itself a sufficient reason to do so. Meanwhile, a reason is content-independent when it motivates conformity irrespective of the nature or character of the action to be done. In other words, it motivates people to behave as if the content-even the moral quality - of the prescribed action was strictly irrelevant to the question of whether it should be obeyed (Hart 1982, 253).

Raz explains that law makes a practical difference in these respects because it is a special kind of reason for action, one that he refers to as a second-order exclusionary reason. Understanding the logic of this class of reasons clarifies how law guides behavior differently from morality. To do so, it is important to distinguish between first and second-order reasons. First-order reasons directly justify and motivate the performance of an action. There may be several first-order reasons for an agent to behave in a certain way. When two first-order reasons come into conflict, they force an agent to decide according to the balance of reasons. After he calculates their 
respective cumulative weights, he determines which alternative is preferable overall and acts accordingly.

In contrast, second-order reasons are grounds to behave or refrain from acting on the basis of first-order reasons. They do not provide direct justifications for action and thus figure into practical reasoning by a different mode of operation (Raz 1990b, 39). For example, a father who makes a promise to buy his daughter whatever she wants for her birthday gives himself a second-order reason to conform to whatever present his daughter's first-order reasons point to. Another example is that of a military general who commands his operatives to retreat from battle. The command serves as a first-order reason to retreat, but it also functions as a second-order reason to disregard other first-order reasons that may factor into their deliberation. For instance, his operatives may disagree with the command because retreating from battle is perceived as an act of cowardice or because they believe that they are close to victory. Even though they may be correct while the general may be wrong, his command overrides the reasons of his men not because it carries greater weight in the balance of first-order reasons, but because it is a second-order reason for his men to not act on their firstorder reasons.

An exclusionary reason is a second-order reason to refrain from acting on firstorder reasons. As we have seen, promises and commands are examples of exclusionary reasons because they direct an agent to disregard the balance of reasons even against their private or better judgment. Law, in this sense, is an exclusionary reason. It excludes all first-order reasons, including moral ones, from emerging as the determining factors of what people decide to do. Individuals have no liberty to disregard them, even against their personal preferences or at the cost of undesirable consequences. Hence, law, by definition, cannot be defeated by any first-order reason. Otherwise, people would be permitted to disobey it whenever they see fit. It would then become conceptually indistinguishable from morality, and legal reasons would not be normatively different from any other kind of first-order reason.

\section{PRACTICAL REASON}

The discussion of the essential features of law clarifies how it fills in some of the gaps of morality as a source of practical reason: it makes difficult decisions on behalf of individuals, it defines objective standards of conduct, and it solves large-scale coordination problems.

\section{Law Makes Decisions on Behalf of Individuals}

One aspect of practical reason involves adopting personal rules of behavior. To act according to a rule is to conform to it regardless of the circumstances, even when there are valid reasons to act contrarily. By adopting such rules, people no longer have to contemplate their course of action each time they are faced with making a particular choice. They simply have to refer to what the rule says they should do. For example, a woman might have adopted a rule never to consume meat because she believes that slaughtering animals for food is unethical. In doing so, she has pre-determined that 
every time she eats in a restaurant, she will only order salads or other vegetarian items on the menu. She will never have to decide again whether she will order an entrée with beef, pork, or chicken, regardless of how appetizing they appear.

Most, if not all, individuals adopt general rules of behavior, many of which are moral. We have seen, however, that there are many reasons why people fail to conform to these rules. They may be formulated at such a high level of generality that they are indeterminate, compete against incommensurate values, or simply prove antithetical to one's self-interest. In the previous example, we saw how Smith hesitated not only about which drowning twin to attempt to rescue but whether he should even attempt saving one at all. In his moment of indecision, he cited his poor ability as a swimmer as a reason to exempt himself from following the general rule to save a person in danger. On this occasion, morality by itself does not have sufficient force to compel him to act in accordance with that rule. The instinct to preserve his own life may have been too overwhelming.

This is where law comes in. Law figures into practical reason by making decisions for people in advance, even against their self-interest or better judgment. It eliminates the need for people like Smith to re-examine their obligations on every occasion in which they apply (Raz 1978, 140). For example, it might be the case that Smith lives in a common law system where tort law recognizes a duty to rescue persons in need or in a particular jurisdiction that enforces Good Samaritan laws that require citizens to help strangers in need. In these situations, law is an institution that creates an obligation for Smith to rescue one of the twins independent of his moral obligation. The fact that he will be liable for refusing to extend aid to a drowning child becomes an additional reason to do the right thing. As a source of authority, Law has made the decision for Smith on how he should react in such a situation. Moreover, precisely because it is authoritative, it functions as a second-order reason for action to save the child that excludes first-order reasons of fear.

It will not matter whether his motive in rescuing them remains pure; he may simply swim out to save them due to prudential reasons. Sometimes, the law may even determine which twin he ought to save. It might be the case, for instance, that Smith is a teacher accompanying his students on a field trip to the beach and that only one of the drowning twins is his student. If this were the case, he would then have a special duty to act in loco parentis by his student instead of the other. In this scenario, law can accomplish what morality cannot, and that is to determine the content of Smith's obligation in his moment of indecision.

\section{Law Defines Objective Standards of Conduct}

A second way in which law enters into practical reason is by establishing objective standards of conduct. We have seen that phrases such as 'good citizen' or 'right treatment' are vague because moral terms are opaque. Consequently, actionguiding principles such as 'Be a good citizen' or 'Treat employees rightly' often require further interpretation.

Law addresses such problems by defining objective standards of conduct in relation to action-guiding principles. It is, however, objective only in a qualified sense; 
it only defines 'good' or 'right' relative to its own conventions rather than claim to reflect what is good or right in the absolute or meta-level sense. Oftentimes, these conventions reflect the publicly shared criteria that make a person or object worthy of commendation. Hence, law need not make any ambitious ontological assumptions about the existence of objective moral principles that are independent of its internal rules and logic. For example, a good citizen might be thought of as one who fulfills a moral obligation to give what is owed to other members of the community. Law streamlines this moral obligation by creating a legal duty to pay taxes. However, even this relatively specific obligation is by itself inchoate apart from law; it has no real content until the amount or rate of tax is fixed by an institutional authority (Honoré 1993, 5). Thus, a good citizen is defined in terms of paying the pre-determined tax rate - a requirement that is established on the basis of social convention rather than abstract moral principles. Similarly, the 'right treatment of employees' becomes defined in terms of paying the minimum wage, incorporating health benefits into their contract, providing adequate work conditions, and other social-fact criteria that are associated with what it means to be a good employer. Unlike morality, therefore, law possesses the resources to take social norms and conventions and to institutionalize them as legal norms (Marmor 2009, 50-52).

Law also has the unique capacity to give an amorphous bundle of moral standards and conventions some fixed and explicit formulations (MacCormick 2007, 23). As we have seen, a problem with morality is that it often operates on a high level of generality; there is sometimes no single way of formulating a general principle to apply to a concrete situation. The result is that morality is often vague; it may provide a general idea of how one ought to act but remain silent on what specifically he ought to do. Even if one were to ask a group of like-minded individuals to articulate their understanding of a certain moral principle, they might articulate slightly different versions of the same moral views and fail to arrive at an agreement about what morality requires. Fortunately, law remedies the symptoms of vagueness by codifying vague moral norms into constitutional provisions, legislative statutes, and judicial decisions. In other words, what were once unwritten, vague, and nebulous moral norms become enshrined as written, objective, publicly ascertainable standards of behavior that spell out what individuals ought to do. It is precisely these public standards that provide the semantic criteria for determining what terms such as 'good' or 'right' mean in concrete situations.

In this sense, law makes abstract action-guiding principles more determinate. Doing so relieves individuals of the burden of having to deliberate on the moral worth of an action or interpret the meaning of vague moral terms. In effect, though it is not conceptually necessary, law directs them to behave in ways that are moral. Once again, law is a supplementary mechanism that helps individuals achieve their moral aims without itself relying on the logic of morality.

\section{Law Solves Coordination Problems}

A third way in which law figures into practical reason is by solving coordination problems. As it has been shown, a person's sense of right and wrong may be substantially shaped by his personal experiences, which in turn may result in 
widespread disagreement. Not everyone, for instance, will agree that they have a moral obligation to contribute to the alleviation of poverty or the preservation of the environment. Moreover, even if they could agree that there was some kind of obligation, there would still be substantive disagreement about how to fulfill it. In these situations, morality by itself cannot settle whose viewpoint is "right" nor organize competing interests in a manner that benefits all. This gap becomes particularly pronounced in the context of large-scale coordination problems wherein people who have highly divergent beliefs, values, and interests must cooperate to achieve a shared moral goal.

Law, however, is equipped to solve problems of this sort because it is a special kind of social institution. Unlike morality, whose binding force may increase or diminish relative to the degree to which an individual accepts it, law purports to be universally binding upon all members of a community regardless of their attitude towards it. Thus it has been said that the capacity to settle coordination problems for a community effectively is an essential feature of a body that claims supreme authority (Finnis 1980, 246). Law, for example, is capable of securing the societal cooperation necessary to enforce anti-pollution schemes, either by disallowing individuals from using automobiles that do not pass emissions tests or giving tax incentives to corporations that invest in green technology. It is just as capable of requiring people to pay taxes under the threat of fines and determining which social welfare programs the revenue should be allocated to. Thus, it becomes easier to attain the overall social goal of improving the general welfare once everyone's actions have been synchronized, compared to a scenario where everyone acts according to their own moral lights but only contributes to society in a piecemeal fashion. In this sense, a morally imperfect world with law may be preferable to an ideal moral world without law, as it is more likely to achieve some collective moral aims.

However, the settlement function of law need not be limited to widespread coordination problems, which tend to be more practical in nature. It can also be used to settle theoretical moral disagreements, not necessarily by providing the "best" moral word but the final one. In an increasingly progressive society, for instance, more and more people may be willing to tolerate the practice of abortion. Inasmuch as much as people uphold the value of life, there are others who see the moral value in saving an unborn baby from being condemned to a life where it is unloved, unwanted, and perhaps even abandoned. As discussed, morality may not have the resources to settle such widespread disagreement precisely because the nature and content of morality itself are being contested. And indeed, it is not difficult to imagine that several women with unexpected pregnancies are genuinely concerned about doing the moral thing but are at a complete loss about what to do. A different normative system such as law is necessary to settle the moral debate, not by declaring which view is morally superior but by making a moral stand of its own. Moreover, in doing so, it may authorize the establishment of abortion clinics that women may access or, conversely, encourage women with unwanted pregnancies to put up their children for adoption instead and increase funding for state orphanages. This is not to say that a society that makes a legal stand on contentious issues is capable of settling a theoretical moral disagreement, only that it may rescue practical reason from moral paralysis. 


\section{CONCLUSION}

This paper has offered some explanations of how law figures into practical reason in ways that morality cannot. First, it makes difficult decisions on behalf of people by creating special duties and obligations, which resolves the problem of indeterminacy which, in turn, generates indecisiveness. Second, it defines objective standards of conduct by translating action-guiding principles into concrete norms of behavior, which addresses the vagueness created by moral terms such as 'good' and 'right.' And third, it solves coordination problems and settles theoretical disagreements that arise from the subjective dimension of morality, thereby making it easier to attain collective social goals.

It has been argued that law must be conceptually and operationally distinct from morality lest it suffer the same gaps and become a redundant system of guidance. To this end, three of its essential features have been examined in this paper. First, law is, first and foremost, a social institution that claims supreme legitimacy and holds itself to be binding upon citizens regardless of their moral beliefs and values. Second, it claims the authority to make final determinations about which forms of conduct are permitted or sanctioned by its own institutions. And third, law functions as a secondorder exclusionary reason for action that displaces first-order moral reasons for people to act one way or another. In conclusion, law fills in the gaps of morality not by claiming to offer superior moral insight into problems but by guiding human behavior through different rules, institutions, and modes of operation.

\section{NOTE}

1. Schauer clarifies that the coercive mechanisms of law are not limited to punitive sanctions, e.g. imprisonment, fines, etc. Legal institutions also offer incentives such as tax breaks, pensions, medical care, employment, etc. (See Schauer 2015, 110-123).

\section{REFERENCES}

Aquinas, St. Thomas. 1988. On law, morality, and politics. Edited by William Baumgarth and Richard Regan, S.J. Indianapolis: Hackett Publishing Company. Austin, John. 1998. The province of jurisprudence determined. 1832. Indianapolis: Hackett Publishing Company, Inc.

Bloomfield, Paul. Why it's bad to be bad. In Morality and Self-Interest. Edited by Paul Bloomfield. New York: Oxford University Press. pp. 251-271.

Dworkin, Ronald. 2002. Sovereign virtue. Cambridge: Harvard University Press. Finnis, John. 1980. Natural law and natural rights. Oxford: Clarendon Press. Fuller, Lon. 1964. The morality of law. New Haven: Yale University Press. Gardner, John. 2012. Law as a leap of faith. New York: Oxford University Press. Geach, P.T. 1956. Good and Evil. Analysis. 17:2 (Dec). pp. 33-42.

Gensler, Harry. 2018. Ethics: A contemporary introduction. $3^{\text {rd }}$ Ed. New York: Routledge. 
Gorovitz, Samuel et al. 1979. Philosophical analysis. $3^{\text {rd }}$ Ed. New York: Random House, Inc.

Harris, John. 2016. The value of life. In Bioethics: An anthology. Edited by Helga Kuhse.

Udo Schüklenk, and Peter Singer. $3^{\text {rd }}$ Ed. West Sussex: John Wiley \& Sons Ltd. pp. 397-405.

Hare, R.M. 1952. The language of morals. New York: Oxford University Press.

Hare, R.M. 1984. Supervenience. Aristotelean Society Supplementary Volume. 58:1 (Jul). pp. 1-16.

Hart, H.L.A. 1958. Positivism and the separation of law and morals. Harvard Law

Review. 71: 4 (Feb). pp. 593-629.

Hart, H.L.A. 1961. The concept of law. Oxford: Clarendon Press.

Hart, H.L.A. 1982. Essays on Bentham. New York: Oxford University Press.

Honoré, Tony. 1993. The dependence of morality on aw. Oxford Journal of Legal

Studies. 13:1 (Spring). pp. 1-17.

Hospers, John. 1997. An introduction to philosophical analysis. $4^{\text {th }}$ Ed. New York: Routledge.

Lucas, J.R. 1977. Against equality again. Philosophy. 52:201 (Jul). pp. 255-280.

MacCormick, Neil. 2007. Institutions of law. New York: Oxford University Press.

Mackie, J.L. 1977. Ethics: Inventing right and wrong. London: Penguin Books, Ltd.

Marmor, Andrei. 2009. Social conventions: From language to law. Princeton: Princeton University Press.

Moore, G.E. 1971. Principia ethica. 1903. Cambridge: Cambridge University Press. Nagel, Thomas. 1986. The view from nowhere. New York: Oxford University Press.

Nowell-Smith, P.H. 1954. Ethics. Middlesex: Penguin Books, Ltd.

Rachels, James and Stuart Rachels. 2018. The elements of moral philosophy. $9^{\text {th }} \mathrm{Ed}$. New York: McGraw-Hill Education.

Raz, Joseph. 1978. Reasons for action, decisions, and norms. In Practical Reasoning. Edited by Joseph Raz. Oxford: Oxford University Press. pp. 128-143.

Raz, Joseph. 1979. The authority of law. Oxford: Clarendon Press.

Raz, Joseph. 1986. The morality of freedom. New York: Oxford University Press.

Raz, Joseph. 1990a. Authority and justification. 1985. In Authority. Edited by Joseph Raz. New York: New York University Press. pp. 115-141.

Raz, Joseph. 1990b. Practical Reasons and Norms. $2^{\text {nd }}$ Ed. New Jersey: Princeton University Press.

Raz, Joseph. 1994. Authority, law, and morality. In Ethics in the Public Domain. New York: Oxford University Press. pp. 210-237.

Schauer, Frederick. 2015. The force of law. Cambridge: Harvard University Press.

Searle, John R. 1962. Meaning and speech acts. The Philosophical Review. 71:4 (Oct). pp. 423-432.

Shapiro, Scott J. 1998. On Hart's way out. Legal Theory. 4:4 (Dec). pp. 469-507.

Singer, Peter. 1993. Practical ethics. 1979. $2^{\text {nd }}$ Ed. New York: Cambridge University Press.

Van Roojen, Mark. 2015. Metaethics: A contemporary introduction. New York: Routledge.

Williams, Bernard. 1972. Morality. Cambridge: Cambridge University Press. 